\title{
Broken epidural catheter: What next to do?
}

\author{
${\text { Urmila Palaria }{ }^{1, *} \text {, Arpita Das², Charul Jakhund }}^{3}$ \\ ${ }^{1}$ Professor, ${ }^{2,3}$ PG Student, Dept. of Anesthesiology and Critical Care, Government Medical College, Haldwani, Uttarakhand, \\ India
}

*Corresponding Author:

Email: urmila_palaria@rediffmail.com

Received: $01^{\text {st }}$ March, 2017

Accepted: $02^{\text {nd }}$ November, 2017

\begin{abstract}
Introduction of epidural catheters has increased the benefits of epidural block by several folds, permitting extension of neuraxial blockade for extended period of time. Although, it's insertion is safe, but removal may be associated with breakage of fragment of catheter in the epidural space. This is rare but troublesome both for anaesthesiologists and patients. Many a times the fragment is not visualized with available radiological imaging techniques even after being radioopaque. Usually broken fragment lies in the space as an inert foreign body but it's surgical removal becomes mandatory once neurological symptoms develop.
\end{abstract}

Keywords: Epidural block, Epidural catheter, Breakage, Radiological imaging, Neurological symptoms.

\section{Introduction}

Introduction of epidural catheters has increased the benefits of epidural block by several folds, permitting extension of neuraxial blockade for extended period of several hours in the postoperative period and also for providing labour analgesia. However, it's use is not free from the complications of the procedure or device itself like abscess, spinal hematoma, radiculopathy, knot or breakage of the catheter. Although the breakage of an epidural catheter (both during insertion and removal) is rare, but it's a worrisome complication..$^{1}$ On searching literature the first ever reported case of broken retained epidural catheter was by Bonica et al., ${ }^{2}$ since then isolated reports have been done by various authors to create awareness among surgeon and patient. Our case is yet another attempt to increase the awareness regarding this complication.

\section{Case Report}

A 76 year old, $45 \mathrm{~kg}$, female (ASA Grade III), was posted for hemiarthroplasty of left hip joint under epidural anesthesia. She was a chronic smoker for past 45yrs and had chronic bronchitis, which was under control with the treatment. Under full aseptic precaution, in the sitting position, 16 Gauze, $80 \mathrm{~mm}$ Touhy needle (Romsons EPI KIT ${ }^{\circledR}$-SFT) was used to access the epidural space in L3-L4 intervertebral space using the loss of resistance to air technique. The epidural space was identified at $3 \mathrm{~cm}$ and 18 Gauze radio- opaque multihole epidural catheter was advanced cephalad up to $12 \mathrm{~cm}$ at the hub of the needle. While advancing catheter further, resistance was felt, so relocation of the space was decided. Attempt of withdrawing the needle alone followed by withdrawal of the catheter was tried but resistance was encountered. When not successful in removing the needle alone, attempt was taken to withdraw both needle and catheter simultaneously with gentle traction.
In this process the catheter sheared off at approximately $6 \mathrm{~cm}$ from the tip. The distal part of catheter was removed with the needle.

After informing surgeon about the incident, subarachnoid block was administered at L2-L3 space with $3 \mathrm{ml}$ of $0.5 \%$ Bupivacaine heavy. The patient was laid in supine position parallel to the ground and after achievement of sensory level of up to T8 surgery was started which lasted 2 hours. Patient had complete motor recovery after 4 hours of spinal anesthesia and there was no sensory or motor deficit.

Later, C-arm and digital X-ray of lumbar spine both in antero-posterior and lateral position was done but it was unable to detect the retained catheter. Patient remained asymptomatic in the post-operative period and there was no feature of local infection, sepsis, or any neurological deficit. No abnormality was detected on daily neurological examination till the day of discharge.

CT Lumbar spine was done to detect the position of catheter. Three radio-opaque markings of epidural catheter were visible in intramuscular plane at L3-L4 level and one marking was visible in epidural space at the same level. [Fig. 1]

The patient and her attendants were informed and counseled regarding the complication and it's consequences. She was kept under regular follow up with advice to report in the event of any adverse symptom. She remained well at a follow up after three months. 


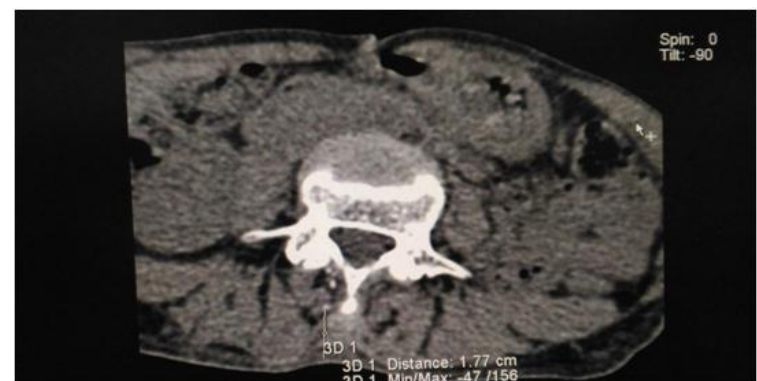

Fig. 1

\section{Discussion}

While the insertion of epidural catheter is usually safe, but they are known to break while removal, leaving a fragment in the epidural space. Epidural catheter breakage has been associated with faulty design, faulty insertion or withdrawal technique, and entrapment by bony or ligamentous tissues during removal. $^{3-5}$ Incidence of breakage of catheter is increased:

1. During insertion excessive length of the catheter has been inserted(should be $<5 \mathrm{~cm}$ )

2. Excessive force is used to advance the catheter against resistance or when it is removed by untrained personnel.

3. When catheter is withdrawn without moving the Tuohy needle or when Tuohy needle is advanced over the catheter.

The catheter gets damaged after getting pinched between the tip of needle and a bony surface. In two levels CSE, the catheter may get sheared off by spinal needle. ${ }^{4}$ The catheter may also tear during withdrawal, as it catches the barbs of an unsharpened needle in an attempt to withdraw it through the introducer needle. It can be due to weakness of the catheter produced by imperfections in manufacturing. ${ }^{6}$ A catheter get looped or knotted by resistance encountered by anatomical obstacles on its path. A catheter can become entangled with nerve roots, vessels, fascia, posterior vertebral arches, vertebral processes and facet joint. ${ }^{7}$ The most likely cause of this entanglement may be the excessive catheter threading. Kinking and twisting of epidural catheter can occur anywhere between the skin and the epidural space. ${ }^{8}$

Radiological imaging tests are not very helpful in locating the catheter even though the catheter is radioopaque. Of these radiographies, computed tomography, magnetic resonance imaging, and ultrasonography all have been used with variable results.

In our case, we could easily locate the broken segment in the lumbosacral spine CT scan anteroposterior and lateral view. No obvious reason for breakage of epidural catheter was obvious in our case but it could be because of shearing of catheter by the needle when attempts were made to withdraw the catheter through Touhy needle.
Sequestered temporary epidural catheter pieces remain generally inert and do not produce a foreign body reaction. The broken fragment usually becomes walled off by fibrous tissue after remaining within the epidural space for about 3 weeks. ${ }^{9}$

Controversy exists over whether retained fragments should be removed or not. For broken epidural catheters, leakage of cerebrospinal fluid, radicular pain, and lumbar stenosis have been reported, but retrieval of fragments may require complex neural and spinal surgery such as vertebral laminectomy., ${ }^{3,5,10,11}$ Surgical removal of the broken fragment is mandatory if the proximal end of the segment is located at or just beneath the skin such that it can be retrieved through a skin incision by gentle traction ${ }^{12}$ or sometimes broken tip is emerging out of the skin, creating a potential entry site for infection of epidural space ${ }^{13}$ through which bacteria can readily track along the catheter remnant. Therefore, in most cases the current standard of management is to leave them alone unless symptomatic as the risk associated with any surgical intervention may be significant. ${ }^{14}$

Our patient was informed and counseled regarding the complications before discharge and was advised to report in case of any adverse symptoms. The patient was closely followed up at regular intervals; till now, she has not developed any complication, after a time period of roughly three months.

\section{Conclusion}

We need to be adhered to the guidelines during catheter's insertion or removal. Catheters should be manufactured with materials that are more easily visualized with the available imaging devices. Biodegradable catheters with high tensile strength made by reliable manufacturers should be used. Documentation of the incidence and proper communication to the patients regarding the consequences of retained epidural fragment is must. Surgical intervention is required only when neurological symptoms develop.

\section{References}

1. R Kasivisvanathan, M Sodhi, S Setty. The broken epidural catheter:to remove or not to remove? British Journal of Hospital Medicine 2012;73:718.

2. Bonica JJ, Backup PH, Anderson CE, Hadfield D, Crepps WF, Monk BF. Peridural block: Analysis of 3,637 cases and a review. Anesthesiology 1957;18:723-84.

3. Ugboma S, Au-Truong X, Kranzler LI, Rifai SH, Joseph NJ, Salem MR. The breaking of an intrathecally-placed epidural catheter during extraction. Anesth Analg 2002;95:1087-9.

4. Sakuma N, Hori M, Suzuki H, Hashimoto Y, Kameyama E, Horinouchi T, . A sheared off and sequestered epidural catheter: a case report. Masui 2004;53:198-200.

5. Noblett K, McKinney A, Kim R. Sheared epidural catheter during an elective procedure. Obstet Gynecol 2007;109:566-8. 
6. Tsui BCH, Finucane B. Tensile strength of 19- and 20gauge arrow epidural catheters. Anesth Analg 2003;97:1524-6.

7. Collier C. Epidural catheter breakage: a possible mechanism. Int J Obstet Anesth 2000;9:87-93.

8. Gough JD, Johnston KR, Harmer M. Kinking of epidural catheters. Anaesthesia 1989;40:1060.

9. Bromage PR. Epidural Analgesia. Philadelphia,WB Saunders.1978 pp 664-6.

10. Staats S, Stinson MS, Lee PP. Lumbar stenosis complicating retained epidural catheter tip. Anesthesiology 1995;85:1115-8.
11. Demiraran Y, Yucel I, Erdogmus B. Subcutaneous effusion resulting from an epidural catheter fragment. $\mathrm{Br}$ J Anaesth2006;96:508-9.

12. De Armendi AJ, Ryan JF, Chang HM, Liu LMP, Jaramillo D. Retained caudal catheter in a paediatric patient. Paed Anaes 1992;2:325-7.

13. Blass NH, RobertsRB, Wiley JK. The case of the errant epidural catheter. Anaesthesiology, 1981; 54:419-421

14. Mitra R, Fleischmann K. Management of the sheared epidural catheter: is surgical extraction really necessary? Journal of Clinical Anesthesia 2007;19:310-4. 